\title{
Analysis of typography in papers from open access Brazilian scientific journals
}

\author{
Maíra Woloszyn, Rosângela Schwarz Rodrigues and Berenice \\ Santos Gonçalves
}

\section{Introduction}

1 Periodical publications are the most efficient way of recording and disseminating scientific research results. So, they are an indispensable source of information for bibliographic research in all areas of human knowledge (Cunha, 2001). Since the emergence of scientific publications, in the middle of the 17th century, the importance of journals in the dissemination of scientific research results has increased considerably, consolidating itself during the 20th century as the main form of disseminating research (Lariviére; Haustein; Mongeo, 2015).

2 Technological advances and the demands of the scientific community have resulted in an evolution in the way scientific journals present information. Initially, scientific journals were distributed in print, and in recent decades, publications have moved towards digital media at an accelerated pace. Moreover, the digital revolution has transformed the way academics create, communicate and preserve scientific knowledge. The distribution of this knowledge optimizes the making of researches, at the same time that they recreate the forms of publication and dissemination of scientific knowledge (Meadows, 1999; Sayão, 2010).

3 Although the digital format has facilitated access, search and navigation of journal papers, the format of the academic journal has not been altered by the digital revolution (Lariviére; Haustein; Mongeo, 2015). Guédon (2001) points out that the indifference of scientists with the digital medium can also be explained by the poor exploitation of resources and the possibilities that it offers. According to the author, 
scientific papers remain exactly as they have been for several centuries: organized based on printed text (Guédon, 2001).

Beyond that, digital publications, regardless of nature, have transformed readers into users, who interact with the content and respond to it in non-linear and often unpredictable ways (Lupton, 2015). As for reading electronic scientific papers, Meadows (1999) claims that the text of a journal paper is not so long that it cannot be read on the screen. However, it is worth considering that reading texts on a screen is more difficult than reading on paper (Kalbach, 2009), as well as the fact that people read about $10 \%$ more slowly on the screen than in printed material (Wood, 2014) and tend to scan the content. So, typography, responsible for composing texts, in digital documents, should facilitate this scanning and improve legibility as much as possible to guide the reader in the navigation of the content (Kalbach, 2009).

With that in mind, this research aimed to identify the application of typography in papers from open access Brazilian electronic scientific journals to evaluate how typography facilitates reading and guides readers through the content. For that, we propose the analysis, based on the typographic properties identified in the literature review, of four articles from scientific journals with different areas of knowledge: general medicine, physics, veterinary medicine, and information science.

\section{Scientific Journals}

6 The first journals were founded in the second half of the 17th century to move forward existing scientific knowledge based on results and consequently avoid duplication of research. They contributed to a more structured and regular distribution of scientific advances, which enabled the systematic archiving of this knowledge (Lariviére; Haustein; Mongeo, 2015).

7 Since its inception, scientific journals have played a central role in the scientific communication process (Sayão, 2010). However, it was during the 20th century that it consolidated its position as the main means of communication to disseminate research, especially in the natural and medical sciences (Lariviére; Haustein; Mongeo, 2015).

Following the technological advances and demands of the scientific community, there was an evolution in the way that scientific journals present information (Meadows, 1999). Initially, scientific journals were distributed in print, in the last decade, scientific publications began to move towards electronic publishing at an accelerated pace. This generated a period of deep transitions, rich in possibilities, but also in questions, tensions and unprecedented problems for the academic world (Sayão, 2010).

9 The electronic scientific journal usually adopts similar methods for the transmission of information from printed journals, however, it has the potential to be more flexible. With the emergence of digital documents, new search strategies, text-based, have facilitated information retrieval. Copying and transferring a scanned document became easy, fast and, in some situations, cheap, in addition to making bibliographic searches more efficient and easy (Guédon, 2001; Meadows, 1999).

10 The classic structure of a scientific journal can be easily reproduced on the screen in addition to leveraging additional resources. For example, the references, in the case of the electronic journal, can be organized so that the materials cited in the text can be retrieved immediately (Meadows, 1999). 
Scientific articles can be configured in different electronic formats, such as HTML, DOC, and PDF (see Figure 1).

Figure 1. Characteristics of digital formats of electronic scientific papers
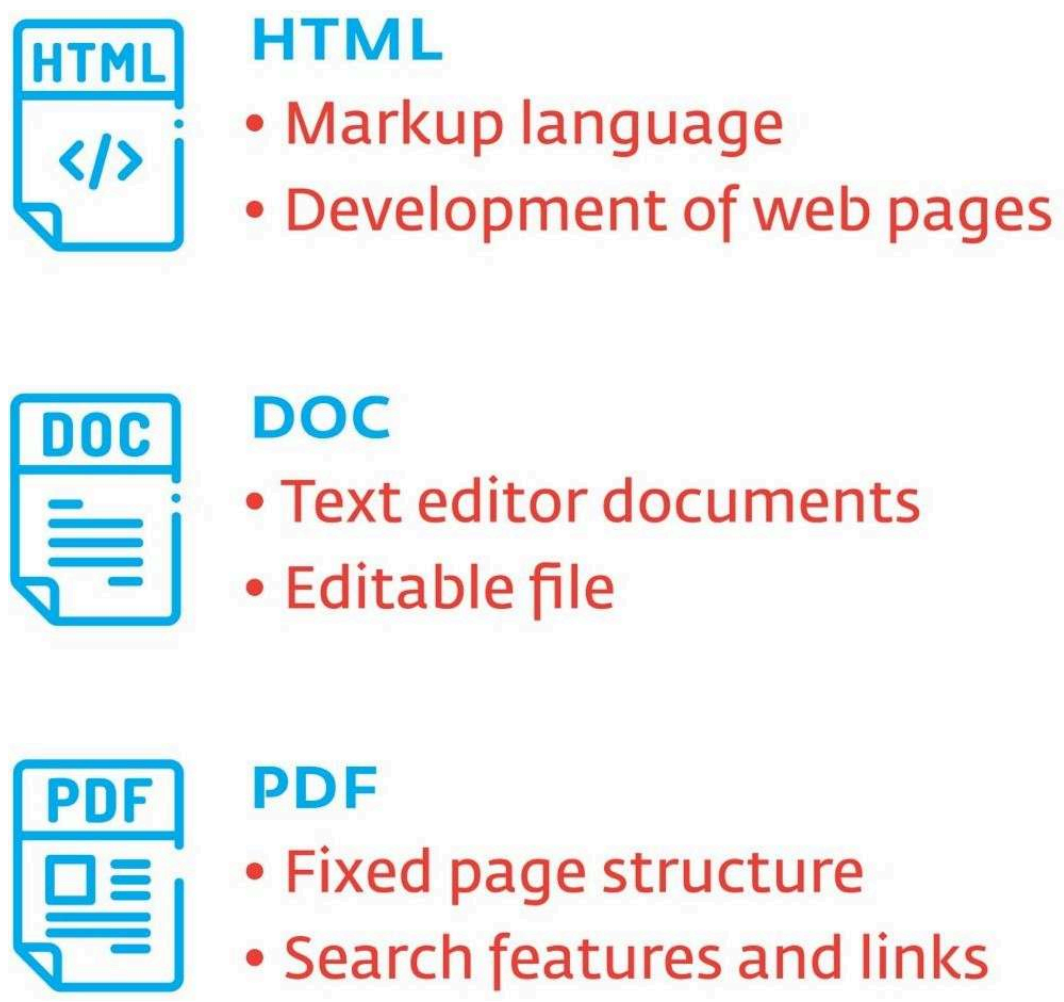

PDF

- Fixed page structure - Search features and links

(Image copyright: authors)

HTML (HyperText Markup Language) is a markup language used to build web pages interpreted by browsers. The DOC format is a file name extension; the documents with this extension are created from text editors. In turn, PDF is the most recurrent format in scientific journals (Silva, 2015).

The PDF (Portable Document Format) emerged in 1991 to allow anyone to capture documents of different natures and send them electronically. That is, to digitize documents that could be displayed on any computer (Adobe, 2017). The format is widely used to make scientific content available in electronic media as it maintains a structure with fixed page numbers, facilitating citations. Thus, it preserves diagramming, typeface, size, among other elements, regardless of the access device and presents search resources and links to complementary content (Silva, 2015).

Although the digital format offers improved access, search, and navigation within and between journal papers, the graphic layout of academic journals has not been altered by the digital revolution. So, PDF has become the established format for electronic journal papers, with the same configuration as the printed format (Lariviére; Haustein; Mongeo, 2015). However, as Meadows (1999) points out, the computer screen differs in size and shape from a printed page. Although the same rules apply regarding the layout and legibility of the printed material, the result will be different. Therefore, the ease of reading will depend on the typeface chosen, its size and the size of the text column (Meadows, 1999). 


\section{Typography}

Understood as the area that studies history, anatomy, development, and use of types, typography is responsible for the composition and configuration of texts in different media. Its development follows the technological potential and limitations of each era. Thus, it is possible to identify several transformations of digital sources to contribute to the particularities of digital media. Currently, studies seek storage savings, to contribute to responsiveness, in addition to providing greater variations in the design of types for users. Therefore, this impacts the user experience, accessibility issues and the quality of digital interfaces (Hudson, 2016; Pamental, 2018).

In scientific journal articles, some typographical aspects reflect how the elements will be arranged to guide the reader in navigating the text (Meadows, 1999). The visual aspects of digital publications must be based on the needs of reading and understanding the content presented. Therefore, the application of typography can be guided by several factors. Many of them are fundamental to facilitate the reading and understanding of the content.

in factors to be considered are legibility and readability. They concern about how readers will read words and texts. Readability is linked to visual comfort; that is, the amount of time the reader dedicates to the text without getting tired. Legibility, on the other hand, is related to the perception and the speed with which an isolated character can be recognized (Farias, 2002).

18 Typographic families generally present weight variations: light, medium, bold and black (Fig. 2).

Figure 2. Variation of weights in a typographic family

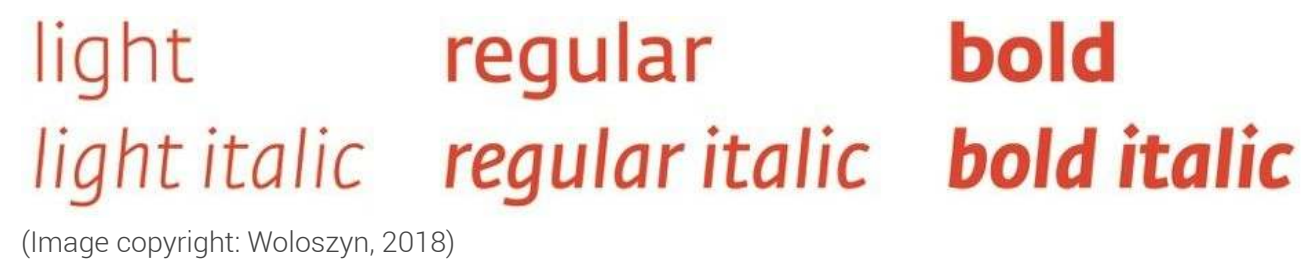

19 Thus, they compose a hierarchical series that is based on the use frequency of typography in texts. Typically bold and italics are used to highlight the flow of text composed, usually, by roman types. Reversing this order can cause physical discomfort to the reader, interfering with readability (Bringhurst, 2015). Therefore, despite the capital letters being the oldest forms of the alphabet and with a simpler design, the lower letters present more variety and visual distinction, favouring readability in long texts (Samara, 2011b).

However, for Bringhurst (2015), the legibility of the letters depends not only on their shape but also on the voids carved between them and around them. This relationship between form and counter form is what defines the spacing for a typographic family, space can be between letters, words, lines of text and paragraphs. 
Figure 3. Letter spacing

\section{tracking}

Standart letter spacing

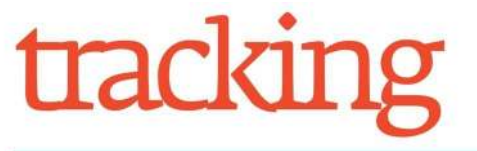

Negative letter spacing

(Image copyright: Woloszyn, 2018)

All of these spaces are essential to create uniformity in the text and minimize distractions for the reader, facilitating the reading and guiding the reader through the content (Samara, 2011a).

Figure 4. Leading spacing

Etiam odio arcu, interdum et ullamcorper et, tempus at orci. Maecenas quis orci a mi pharetra malesuada et in ipsum. Cras in facilisis sapien. Phasellus vel feugiat augue. Sed cursus lacus et lacus pellentesque, at vulputate arcu porta. Sed ac lacus in nisl accumsan convallis. Etiam at mauris ut ligula dapibus pellentesque ullamcorper et dolor.

Positive line spacing

Etiam odio arcu, interdum et ullamcorper et, tempus at orci. Maecenas quis orci a mi pharetra malesuada et in ipsum. Cras in facilisis sapien. Phasellus vel feugiat augue. Sed cursus lacus et lacus pellentesque, at vulputate arcu porta. Sed ac lacus in nisl accumsan convallis. Etiam at mauris ut ligula dapibus pellentesque ullamcorper et dolor.

\section{Equivalent line spacing}

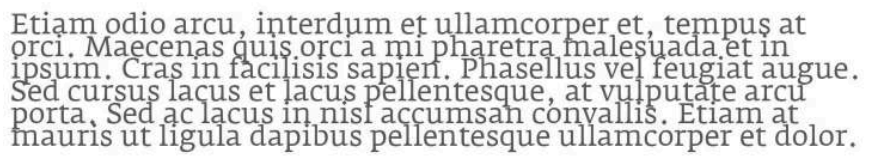

\section{Negative line spacing}

(Image copyright: the author from Woloszyn, 2018)

In this sense, Lupton (2006) argued that typography can guide the reader in navigating the content even in subtle ways, whether from a paragraph indentation, signalling the entry of a new idea or a link or directing the reader to content additional.

Although the principles of classic typography, based on theoretical references about printed publications, can help in understanding the subject with a focus on digital publications, some factors must be reevaluated to ensure reading comfort on the screen. The font size, for example, has different orientations from the existing ones for the printed medium. The reader places his gaze at a greater distance from the screen because of the brightness of the digital display. Still, the brightness of the digital display can also imply inaccurate letters and characters, which reinforces the recommendation for the application of typography in larger sizes (Lupton, 2015). 


\section{Methodological procedures} scientific journals, four examples were selected as objects of study. All of them were accessed and analyzed using a desktop computer. From the Brazilian database SciELO, four journals from different thematic areas were taken. They were chosen according to the highest- ranking of Brazilian journals in their respective areas of the Capes Journal Portal, namely: Revista da Associação Médica Brasileira, from the field of general medicine; Brazilian Journal of Physics, of physics; Pesquisa Veterinária Brasileira, from the area of veterinary medicine and Perspectivas em Ciência da Informação, from information science, all with different chief editors.

From these journals, the second paper published in the June 2019 issue was selected to analyze the typography. Therefore, the selected papers are:

HASHEMI, S. Structure of Hard Ellipses Confined in Hard Wall Square. Brazilian Journal of Physics, v. 49, n.3, p.321-332, 2019

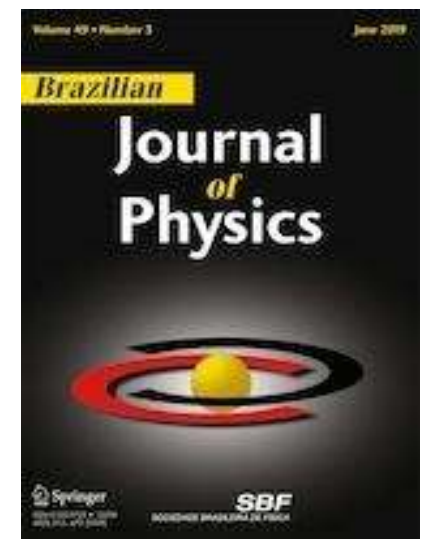

http://www.sbfisica.org.br/bjp/ 
DONG, H.; DU, Y. The study of copy number variations in the regions of PRKAB2 and PPM1K among congenital heart defects patients. Revista da Associação Médica Brasileira, v.65, n.6, p.786-790,

2019.

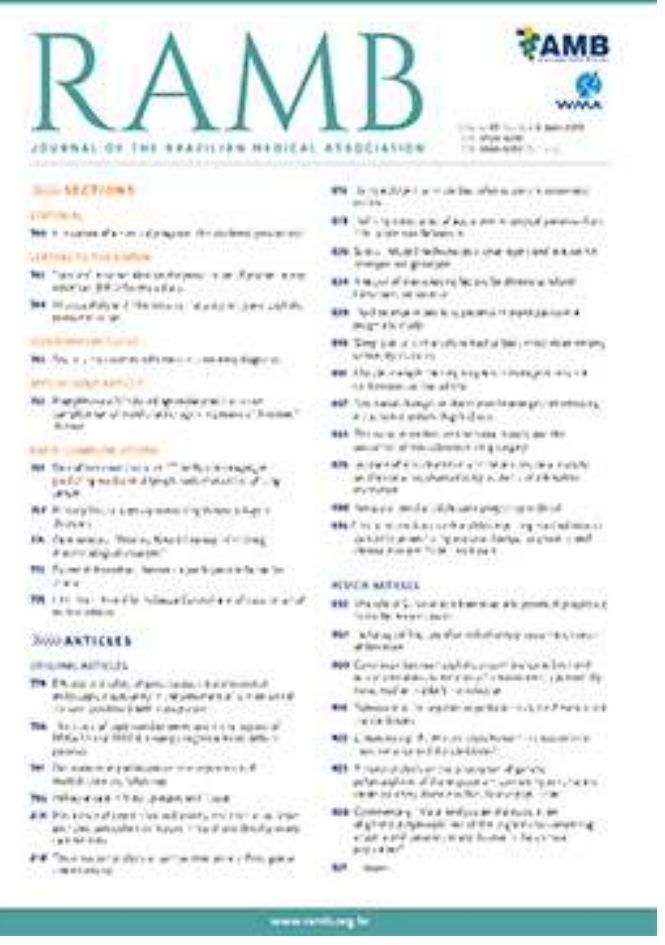

https://ramb.amb.org.br

WITHOEFT, J. A.; et al. Polioencephalomalacia (PEM) in calves associated with ecess sulfur intake. Pesquisa Veterinária Brasileira, v.39, n.6, p.376-381, 2019.

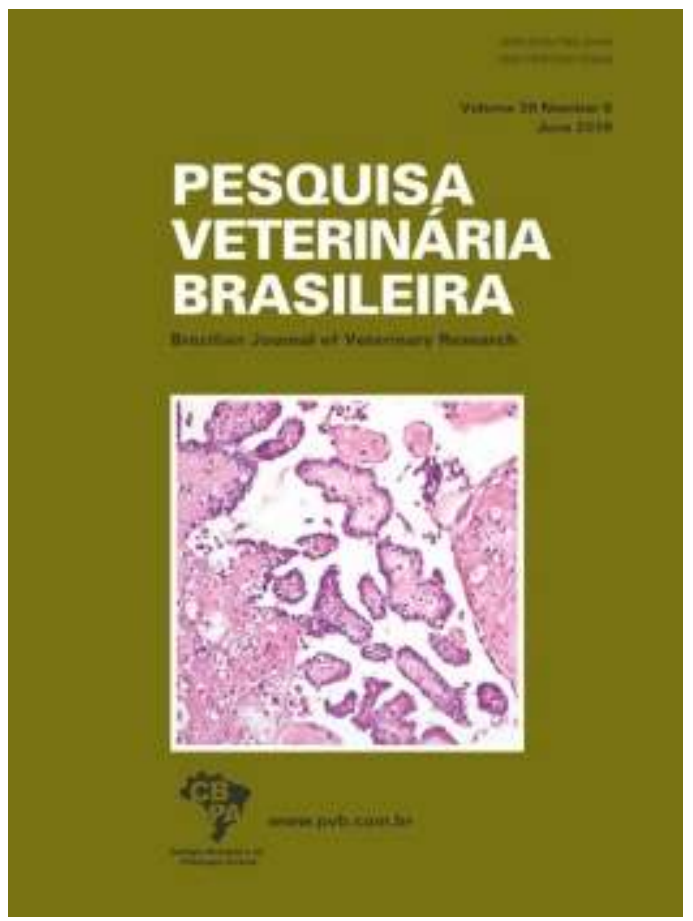

http://www.pvb.com.br 
SILVA, S. E.; et al. Proposta de um construto para gestão da informação no ciclo de vida dos agentes. Perspectivas em Ciência da Informação, v.24, n.2, p. 14-34, 2019.

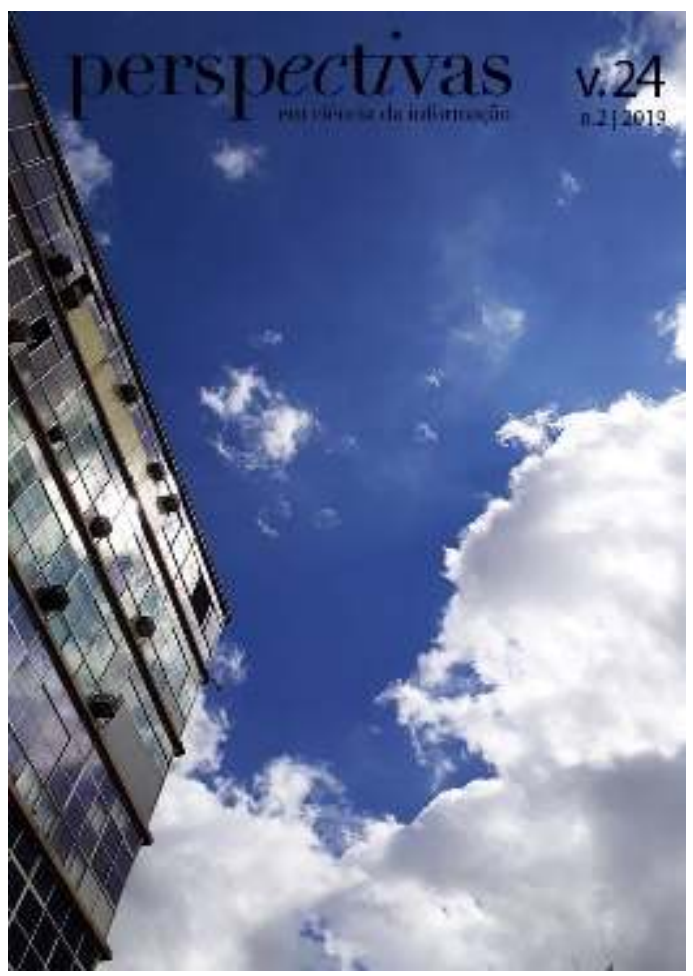

http://portaldeperiodicos.eci.ufmg.br/index.php/pci

The parameters that guided the analyzes were structured based on the notes on typography presented in the theoretical review. Thus, typographic properties were identified and outlined. Table 1 describes the concepts used in the analysis.

Table 1. Synthesis of concepts taken from the theoretical review from the reference authors.

\begin{tabular}{|l|l|l|}
\hline Properties & Authors & Contribution \\
\hline Legibility & Farias, 2002 & Legibility refers to the clarity of the characters in the text. \\
\hline \multirow{2}{*}{ Readability } & Farias, 2002 & $\begin{array}{l}\text { Readability is linked to the reader's understanding of the text and is } \\
\text { essential to ensure reading comfort. }\end{array}$ \\
\hline \multirow{2}{*}{ Spacing } & $\begin{array}{l}\text { Samara, } \\
2011 \mathrm{a}\end{array}$ & $\begin{array}{l}\text { The spaces between letters, words, and lines of a text are essential in } \\
\text { creating uniformity, minimize distractions for the reader and guide } \\
\text { him through the content. }\end{array}$ \\
\cline { 2 - 4 } Size & $\begin{array}{l}\text { Bringhurst, } \\
2015\end{array}$ & $\begin{array}{l}\text { Typographic legibility is not just about the shape of the letters, but also } \\
\text { the empty spaces around them. }\end{array}$ \\
\hline $\begin{array}{l}\text { Lupton, } \\
2015\end{array}$ & $\begin{array}{l}\text { The font size used must be observed because, due to the luminosity, } \\
\text { the distance that the reader positions his gaze from the digital device } \\
\text { is greater than that of a printed publication. }\end{array}$ \\
\hline
\end{tabular}




\begin{tabular}{|l|l|l|}
\hline Hierarchy & $\begin{array}{l}\text { Lupton, } \\
2006\end{array}$ & $\begin{array}{l}\text { Typography can help the reader navigate through the publication's } \\
\text { content, whether with paragraph indentations, links, differences in } \\
\text { sizes or different font style in titles and prominent words. }\end{array}$ \\
\cline { 2 - 3 } & $\begin{array}{l}\text { Bringhurst, } \\
2015\end{array}$ & $\begin{array}{l}\text { Variations in the weight of typographic families give hierarchy to the } \\
\text { texts. Italics and bold weights are used to highlight the flow of Roman } \\
\text { text, as well as capitalized words. Reversing this order can impair the } \\
\text { readability and legibility of text. }\end{array}$ \\
\hline
\end{tabular}

\section{Results and discussion}

The paper from Revista da Associação Médica Brasileira uses two typographic families to compose the layout of the publication, distributed in PDF. The first is a serif font, Unna, which is applied to the body of the text. The other, non-serif, MatoSans, is applied to titles, subtitles, tables, and additional information. The layout of the magazine has two columns for the body of the paper and one column for the "summary" (Figure 5).

Figure 5. Pages of the selected paper in the Revista da Associação Médica Brasileira.

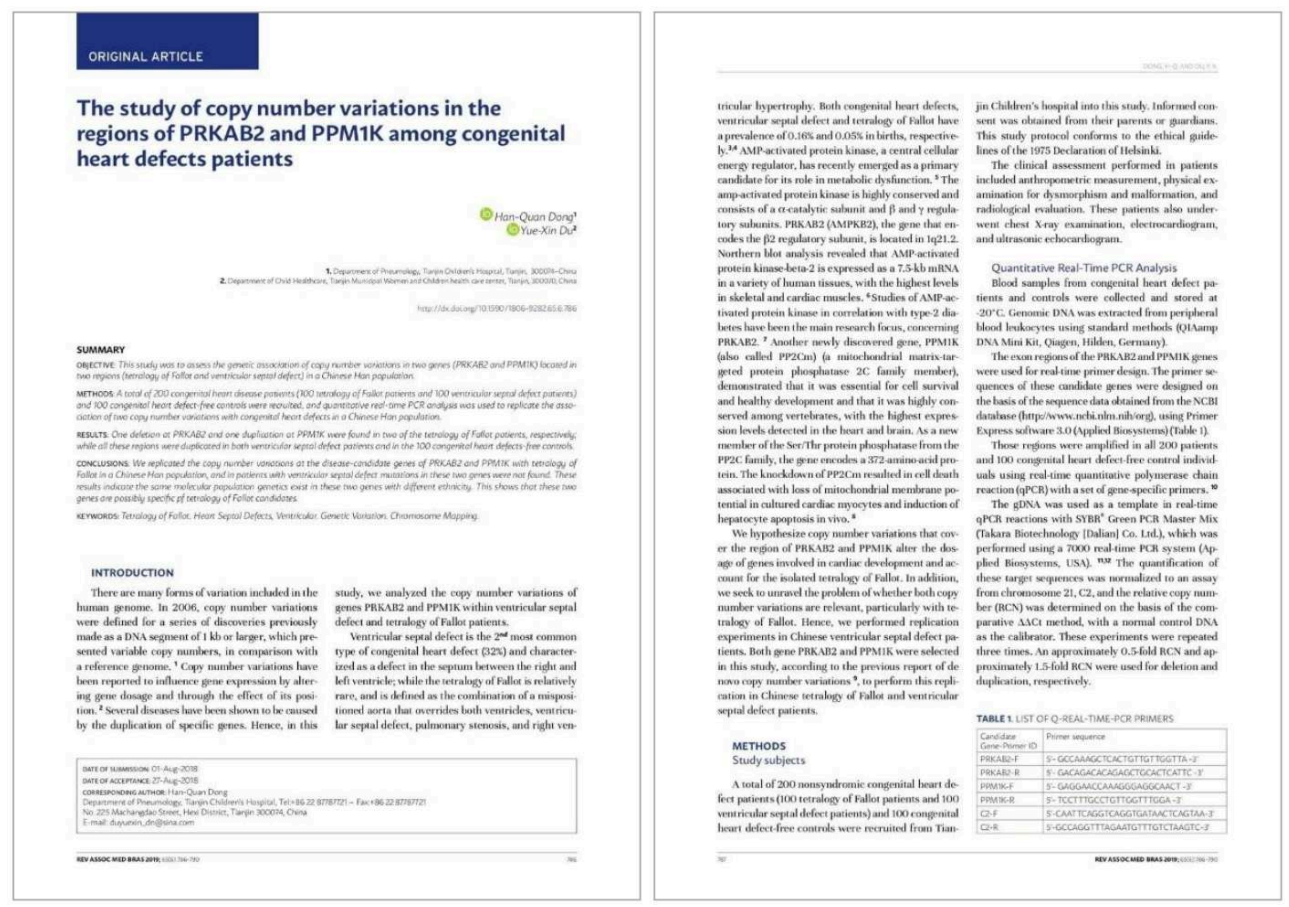

(Image copyright: authors capturing the first two pages of Dong; Du, 2019)

The use of two typographic families helps to compose information hierarchy. The typefaces are different in form - one with serif and the other without it - and they have weight differences, which provides a greater organization of information. Color application (blue) is also used to highlight titles and subtitles in the document. 
Figure 6. Excerpt from the paper of Revista da Associação Médica Brasileira with typographic variations

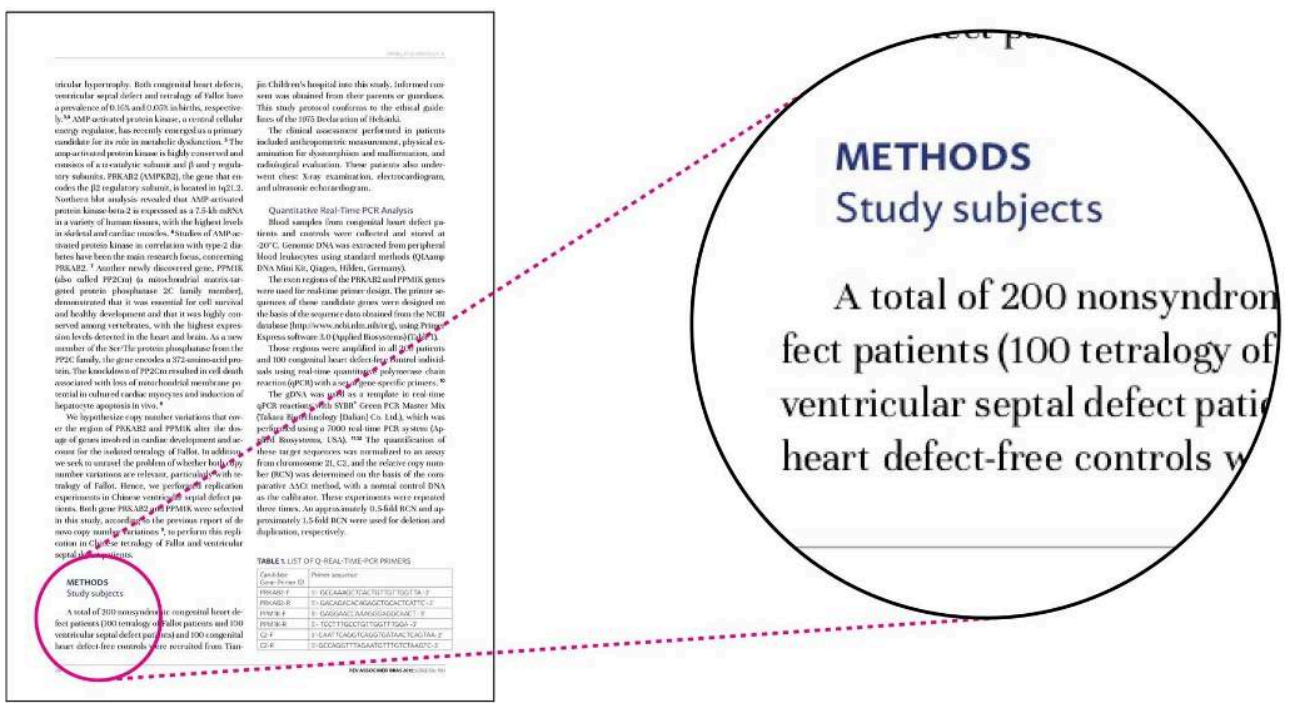

(Image copyright: authors capturing a page from Dong; Du, 2019)

In regards to font sizes, in some additional information, the size is very small. This compromises legibility and readability, even with the possibility of enlargement provided by the PDF format. The text structure is configured in two columns and has legible texts. However, the fonts sizes could be better explored, because the large flow of text makes reading tiresome. The spacing of the text, concerning the font size, is well applied and guides the reader through the content.

The next paper, selected in the Brazilian Journal of Physics, also presents its layout in two columns and uses two typographic families, in PDF. The first typeface, Myriad Pro, without serif, is used in titles and subtitles. The other, with serif, Times New Roman, is applied in the body of the text. Fig. 7 shows the typography application. 
Figure 7. Pages of the selected paper in the Brazilian Journal of Physics.

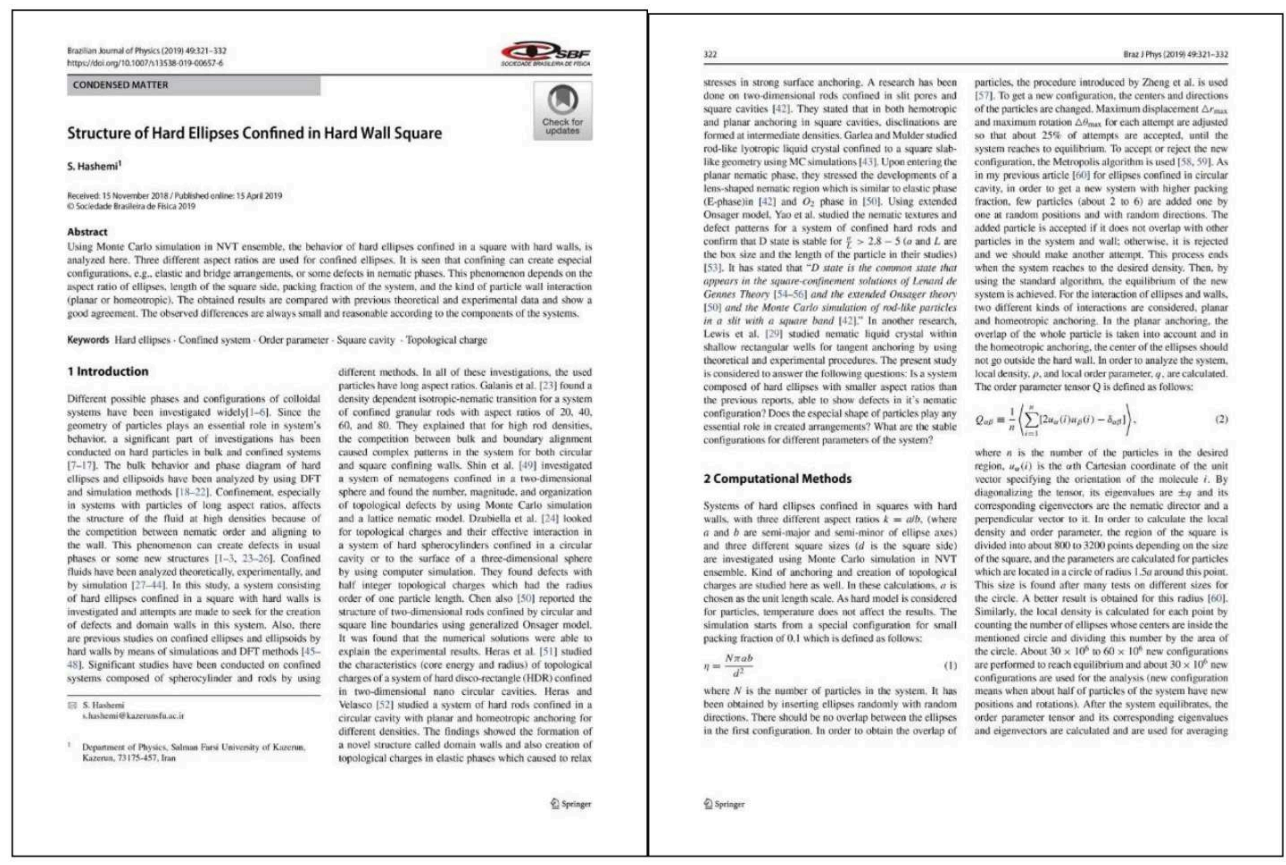

(Image copyright: authors capturing the first two pages of Hashemi, 2019)

The layout proposed by the journal varies the weights of the families mentioned to give hierarchy and organization to the document. For example, the title of the article and the name of the author are in lighter weights. The document's topics are composed of heavier types. Still, they propose a resource for bibliographic references, indicated by numbers in blue (Fig. 8). There is also a link that, when clicked, directs the reader to the bibliographic references at the end of the article.

Figure 8. Excerpt from the selected paper in the Brazilian Journal of Physics.

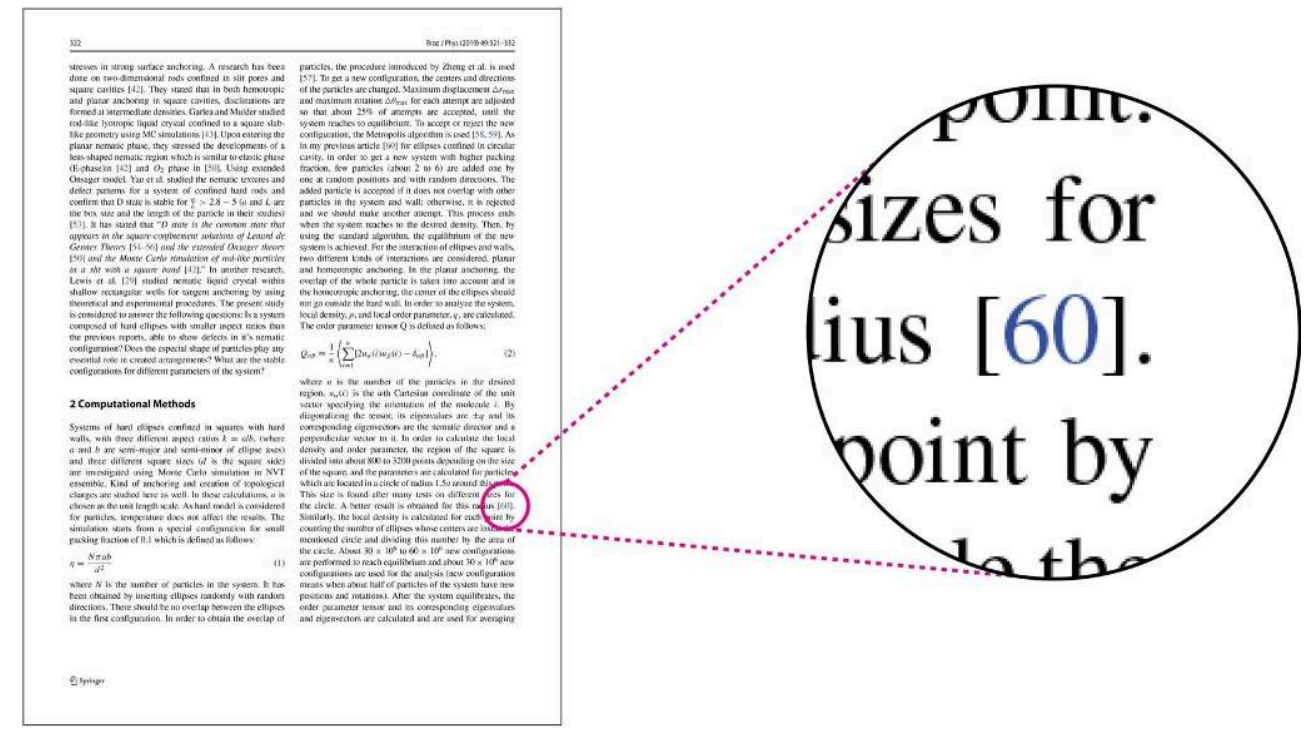

(Image copyright: authors capturing a page from Hashemi, 2019)

The sizes of types used are legible despite being applied in small font sizes. The spacing, concerning the font size, is coherent and helps guide the reader through the text. 
However, with the large flow of text, these smaller font sizes can make reading tiresome.

The selected paper in the Pesquisa Veterinária Brasileira Journal, also available in PDF, presents the abstract in one column and the body of the text in two columns (fig. 9). The texts are composed of a single typeface, Cambria.

Figure 9. Pages of the selected paper in the Brazilian Veterinary Research.

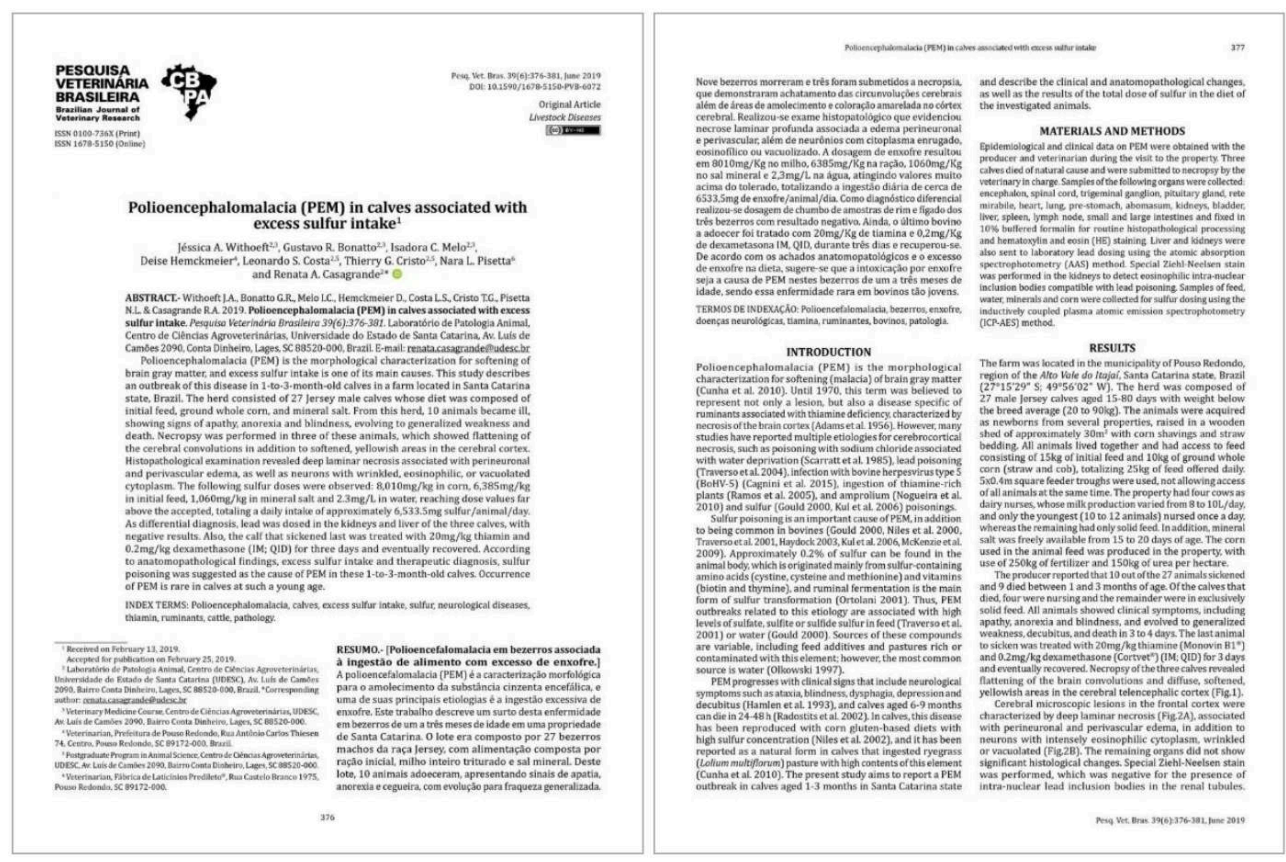

(Image copyright: authors capturing the first two pages of Withoeft et al., 2019).

With the chosen typeface, the document uses weight variations to give hierarchy to the text, applying heavier types in titles and subtitles. The texts are legible, but given that they are divided into two columns the font sizes could be larger to facilitate reading since scientific papers have a lot of content and information. Still, it is noticed the application of font sizes even smaller in the topic "materials and methods" in the document. 
Figure 10. Excerpt from the selected paper in the Pesquisa Veterinária Brasileira.

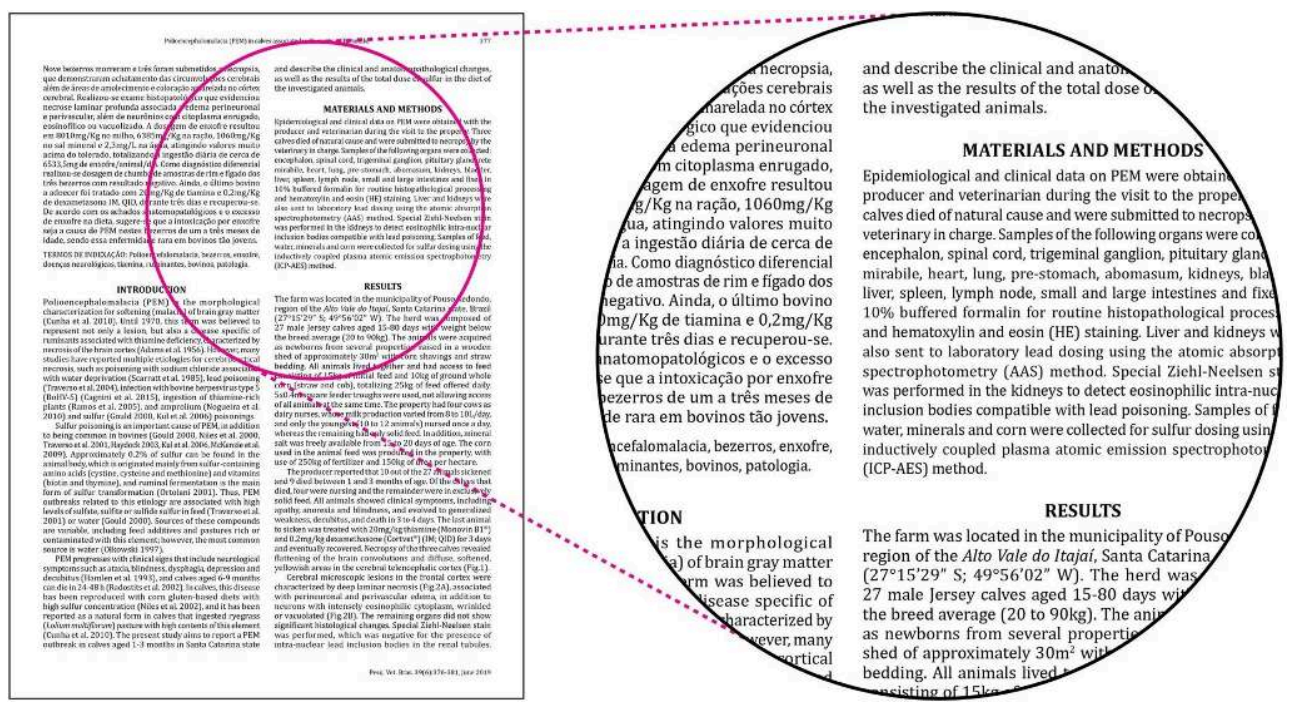

(Image copyright: authors capturing a page from Withoeft et al., 2016)

About the spacing between words, the sizes are consistent, considering the font size. However, because it is a serif typeface family with larger ascendants and descendants, the spacing between lines could be greater to provide greater visual comfort for the reader.

Finally, the paper selected in the Perspectivas em Ciência da Informação Journal has a layout configured in a column, in PDF. The text is composed of an unidentified typeface family without serif.

Figure 11. Pages of the selected paper in Perspectivas em Ciência da Informação.
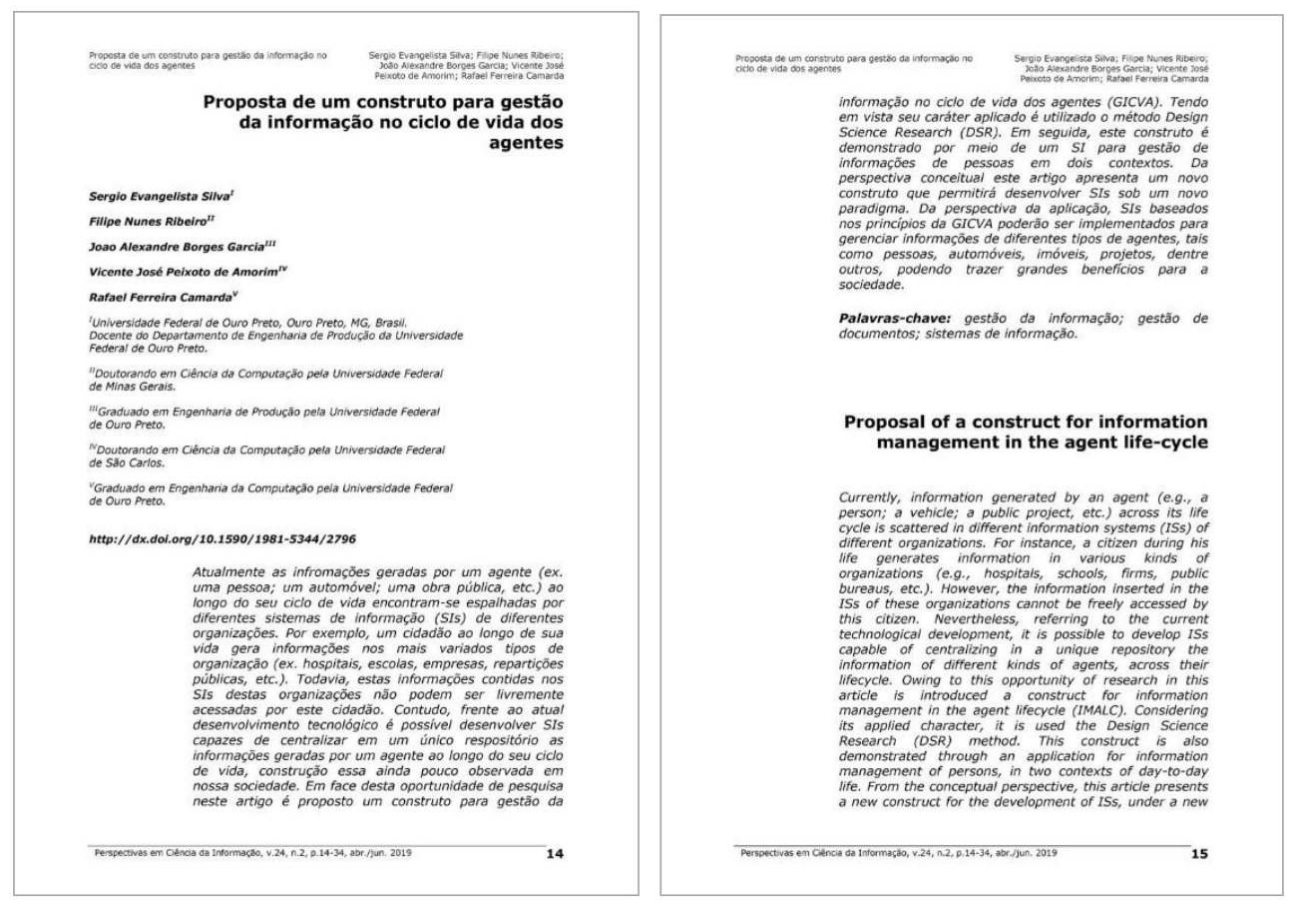

(Image copyright: authors capturing the first two pages of Silva et al., 2019) 
The paper explores the typographic family as from the variation of weights to give hierarchy to the document (Fig. 12). The heavier types are applied to titles and subtitles and italics are used to highlight and compose the abstract in English. The texts have good legibility and readability. The texts have good sizes and spacings suitable for reading from a desktop computer.

Figure 12. Excerpt from the selected paper in the Perspectivas em Ciência da Informação.

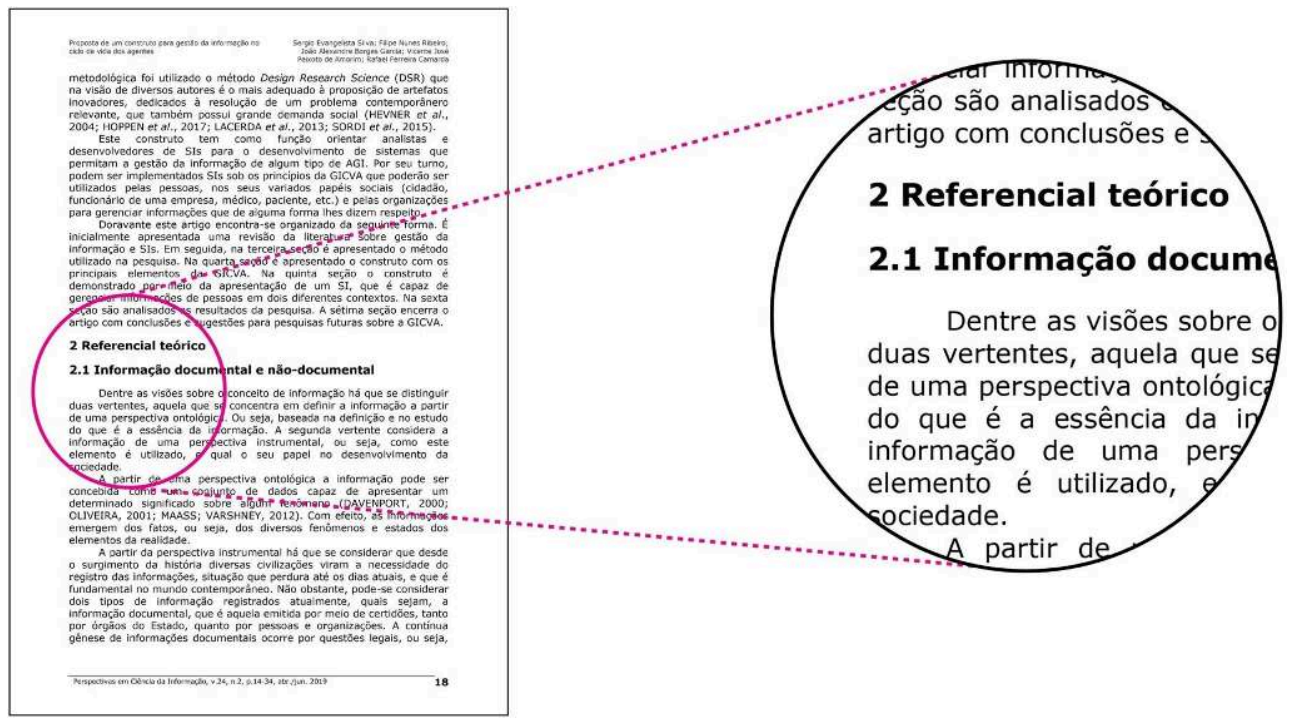

(Image copyright: authors capturing a page from Silva et al, 2019)

When structuring the analysis, it was possible to highlight the typographical aspects of selected papers in scientific journals. It is possible to identify which articles met or not the properties addressed by the authors in the theoretical review. Table 2 compares the results.

Table 2. Summary of the analysis results.

\begin{tabular}{|c|c|c|c|c|c|}
\hline $\begin{array}{l}\text { Typographic } \\
\text { properties }\end{array}$ & Legibility & Readability & Spacing & Size & Hierarchy \\
\hline $\begin{array}{l}\text { Revista da } \\
\text { Associação } \\
\text { Médica } \\
\text { Brasileira }\end{array}$ & $\begin{array}{l}\text { Meets } \\
\text { partially. } \\
\text { Some texts } \\
\text { are } \\
\text { practically } \\
\text { unreadable. }\end{array}$ & $\begin{array}{l}\text { Meets } \\
\text { partially. } \\
\text { With the large } \\
\text { flow of text, } \\
\text { some sizes } \\
\text { applied can } \\
\text { make reading } \\
\text { tiresome. }\end{array}$ & $\begin{array}{l}\text { Meets. } \\
\text { Regarding the } \\
\text { font sizes, the } \\
\text { spacing is } \\
\text { consistent. }\end{array}$ & $\begin{array}{l}\text { Meets partially. } \\
\text { Some } \\
\text { information is } \\
\text { presented in } \\
\text { very small sizes. } \\
\text { The size applied } \\
\text { to the text is } \\
\text { legible; however, } \\
\text { it is a little small } \\
\text { due to the } \\
\text { content flow. }\end{array}$ & $\begin{array}{l}\text { Meets. } \\
\text { Uses variations } \\
\text { of typeface and } \\
\text { colour to give } \\
\text { hierarchy and } \\
\text { highlights to } \\
\text { the text. }\end{array}$ \\
\hline
\end{tabular}




\begin{tabular}{|c|c|c|c|c|c|}
\hline $\begin{array}{l}\text { Brazilian } \\
\text { Journal of } \\
\text { Physics }\end{array}$ & $\begin{array}{l}\text { Meets. } \\
\text { The } \\
\text { characters } \\
\text { are legible. }\end{array}$ & $\begin{array}{l}\text { Meets } \\
\text { partially. } \\
\text { The text size is } \\
\text { relatively } \\
\text { small to the } \\
\text { content flow, } \\
\text { which can } \\
\text { result in visual } \\
\text { discomfort for } \\
\text { the reader. }\end{array}$ & $\begin{array}{l}\text { Meets. } \\
\text { Regarding the } \\
\text { font size, the } \\
\text { spacing is } \\
\text { consistent. }\end{array}$ & $\begin{array}{l}\text { Meets partially. } \\
\text { The size of the } \\
\text { texts allows } \\
\text { reading, but they } \\
\text { could be better } \\
\text { adapted to } \\
\text { improve } \\
\text { legibility. }\end{array}$ & $\begin{array}{l}\text { Meets. } \\
\text { It uses a variety } \\
\text { of weights and } \\
\text { italics to } \\
\text { highlight and } \\
\text { organize the } \\
\text { text. It } \\
\text { identifies links } \\
\text { with the colour } \\
\text { change in the } \\
\text { typography. }\end{array}$ \\
\hline $\begin{array}{l}\text { Pesquisa } \\
\text { Veterinária } \\
\text { Brasileira }\end{array}$ & $\begin{array}{l}\text { Meets. } \\
\text { The } \\
\text { characters } \\
\text { are legible. }\end{array}$ & $\begin{array}{l}\text { Meets } \\
\text { partially. } \\
\text { The size of the } \\
\text { texts could be } \\
\text { larger to } \\
\text { facilitate } \\
\text { reading } \\
\text { comfort. }\end{array}$ & $\begin{array}{l}\text { Meets } \\
\text { partially. } \\
\text { Line spacing } \\
\text { compromises } \\
\text { readability. }\end{array}$ & $\begin{array}{l}\text { Meets partially. } \\
\text { The font sizes } \\
\text { could be larger } \\
\text { tor facilitate } \\
\text { reading, given } \\
\text { ther massive } \\
\text { amount of } \\
\text { information. }\end{array}$ & $\begin{array}{l}\text { Meets. } \\
\text { It uses the } \\
\text { variation of } \\
\text { weights to give } \\
\text { hierarchy to the } \\
\text { text. }\end{array}$ \\
\hline $\begin{array}{l}\text { Perspectivas } \\
\text { em Ciência } \\
\text { da } \\
\text { Informação }\end{array}$ & $\begin{array}{l}\text { Meets. } \\
\text { The } \\
\text { document } \\
\text { has good } \\
\text { legibility. }\end{array}$ & $\begin{array}{l}\text { Meets. } \\
\text { The document } \\
\text { has good } \\
\text { readability. }\end{array}$ & $\begin{array}{l}\text { Meets. } \\
\text { Spacing is } \\
\text { consistent } \\
\text { with the size } \\
\text { of the types. }\end{array}$ & $\begin{array}{l}\text { Meets. } \\
\text { It has a type size } \\
\text { suitable for } \\
\text { viewing and } \\
\text { reading from a } \\
\text { desktop r } \\
\text { computer. }\end{array}$ & $\begin{array}{l}\text { Meets. } \\
\text { Applies the } \\
\text { variation of } \\
\text { weights and } \\
\text { italics to give } \\
\text { highlights and } \\
\text { hierarchy to the } \\
\text { document. }\end{array}$ \\
\hline
\end{tabular}
computer, it was identified that all use the PDF format for distribution. During the analysis, it can be observed that the documents explore typography when building the organization of the texts and, in this way, guide the reader through the content. About the typographic hierarchy, the four articles analyzed met the guidelines punctuated by the literature.

It was also noted that, in general, the factor that most influenced the legibility and readability of papers was the font size. The papers configured in two columns, Revista da Associação Médica Brasileira, Brazilian Journal of Physics and Pesquisa Veterinária Brasileira, presented texts with smaller types, which compromises reading comfort. Lupton (2015) explains it is necessary to consider the distance that the reader is positioned from a digital device, as well as their luminosity. Thus, implies larger types so that they are legible and comfortable for the reader.

This also reinforces what some authors (Lariviére; Haustein; Mongeo, 2015; Guédon, 2001) claim, that the documents available for reading on-screen replicate the same layout of the printed publications. In this sense, the use of typographic guidelines is perceived, as to the font size, closer to those existing for the printed medium than for the digital medium. However, as Meadows (1999) points out, although papers in 
electronic scientific journals applied the same rules regarding the layout and legibility of printed material apply, the result will be different.

In regards to the spacing, it is observed that only one journal (Pesquisa Veterinária Brasileira) presented spacing that can hinder the legibility of the texts, which may be linked to the fact that the brightness of the digital devices makes the letters inaccurate (Lupton, 2015). That, added to the chosen typeface, makes the characters visually require more space between lines and characters.

Comparing the four articles analyzed, concerning the use of typography, the configuration of the journal Perspectivas em Ciência da Informação stands out. It met all the evaluated principles. Still, it is worth mentioning that, unlike the others, he presented the diagram in one column. In digital media, this factor can contribute to the reading comfort of the reader. It should be noted that, because they use the vertical page format, scientific papers depend on a scroll to access the content. Therefore, when configured in two columns, the reader needs to go back and forth from the top to the end of the page to access the content instead of following a continuous flow, as in one column layouts.

On the other hand, the paper that presented the greatest possibilities for adjustments was the Journal Pesquisa Veterinária Brasileira, completely complying with only one of the evaluated principles. The other journals, Revista da Associação Médica Brasileira and Brazilian Journal of Physics, completely complied with two evaluated principles and presented possibilities to the other two.

The analysis points out some factors that influence the application of typography in electronic scientific journal papers. Fig. 13 summarises these factors.

Figure 13. Typography factors in electronic scientific journal papers.

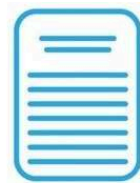

\section{ONE COLUMN}

\section{TYPOGRAPHY IN PAPERS \\ FROM ELECTRONIC SCIENTIFIC JOURNALS}

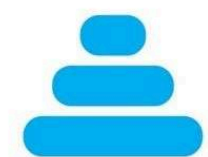

TYPOGRAPHIC HIERARCHY

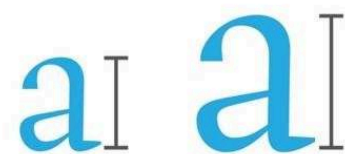

BE CAREFUL WITH

SIZES AND SPACING

(Image copyright: authors) 
Thus, the study made it possible to indicate some guidelines for the typography application in papers on electronic scientific journals. Table 3 presents these guidelines.

Table 3. Guidelines for typography application in electronic scientific journal papers.

\begin{tabular}{|l|l|}
\hline \multicolumn{2}{|l|}{ Guidelines for the typography application in electronic scientific journal papers } \\
\hline Layout & $\begin{array}{l}\text { The configuration of the text in only one column favors the reading in the digital } \\
\text { environment. }\end{array}$ \\
\hline $\begin{array}{l}\text { Legibility and } \\
\text { Readability }\end{array}$ & $\begin{array}{l}\text { The main problems of legibility and readability of texts are due to very small } \\
\text { font sizes and spacing. Therefore, the use of types slightly larger than those } \\
\text { applied to printed media, as well as more ventilated lines, help ensure reading } \\
\text { comfort. }\end{array}$ \\
\hline Hierarchy & $\begin{array}{l}\text { The typographic and information hierarchy are important parts of this type of } \\
\text { document. Because they help guide the reader through the content, as well as } \\
\text { give rhythm to the reading. }\end{array}$ \\
\hline
\end{tabular}

Finally, the validity of the analysis process carried out is emphasized. The table organized for such a process proved to be systematic and adequate to identify and evaluate the application of typography in papers in electronic scientific journals. Also, the organization of results in this way provided an overview of the analysis in the different papers. This allowed identifying guidelines for typography that should be considered to achieve a higher level of adequacy and quality.

\section{Final considerations}

Scientific journals allow the recording and dissemination of research results. Therefore, they are indispensable sources of information in the scientific environment. With technology advancement, new possibilities have also emerged for scientific journals, such as ease of access, search and data retrieval. However, for the most part, the shape of scientific papers remains the same, based on the printed publication.

With the aforementioned analysis, it is clear that, despite being publications focused on the digital medium, most papers are still configured more closely to the existing guidelines based on the printed medium. Also, it is noted that the interactive resources existing in digital media are not explored by scientific papers. Only one of the analyzed documents presented the typography as a link, directing the reader to the cited bibliographic reference in the text flow.

51 Thus, it is worth mentioning that the classic literature of typography, based on its application for printed media, is not sufficient to understand the behaviour of this resource in digital media. With that, it is proven the need for studies that explore the possibilities of typography in electronic publications to improve reading comfort from digital devices, and, mainly, as additional resources.

The present research was based on examples of Brazilian open access scientific journals. However, it is understood that the guidelines indicated on the typography 
application in these documents also extend to international publications. Finally, it is emphasized that the analysis of the papers was conditioned to the researcher's perspective and vision.

About the analysis process, it is noteworthy that the organization of the table was considered adequate to identify how typography has been applied in papers from electronic scientific journals and it also allowed an overview of the results, demonstrating the potential of the strategy used. However, it should be noted that the table can be improved and refined for future research, bringing other aspects not covered in this scope and taking into consideration a broader study.

\section{BIBLIOGRAPHY}

Adobe. 2017, acrobat.adobe.com/br/pt/why-adobe/about-adobe-pdf.html.

Bringhurst, Robert. Elementos do estilo tipográfico. São Paulo: Cosac Naify, 2015.

Cunha, Murilo B. Para saber mais: fontes de informação em ciência e tecnologia. Brasília: Briquet de Lemos, 2001.

Farias, Priscila. "Legibilidade e tipografia." Tupigrafia 3, 2002.

Guedon, Jean-Claude. Oldenburg's Long Shadow: Librarians, Research Scientists, Publishers, and the Control of Scientific Publishing, Association of Research Libraries, 2001, http://www.arl.org/ resources/pubs/mmproceedings/ 138guedon.shtml

Kalbach, James. Design de navegação web. Porto Alegre: Bookman, 2009.

Larivière, Vincent, et al. "The Oligopoly of Academic Publishers in the Digital Era." PLoS ONE, edited by Wolfgang Glanzel, vol. 10, no. 6, June 2015. doi:10.1371/journal.pone.0127502.

Lupton, Ellen. Pensar com tipos. São Paulo: Cosac Naify, 2006.

Lupton, Ellen. Tipos na tela. São Paulo: Gustavo Gili, 2015.

Meadows, Arthur Jack. A comunicação científica. Brasília. Briquet de Lemos, 1999.

Mugnaini, Rogério, \& Población, Dinah A. de Melo Aguiar. "Multidisciplinaridade e especificidade na comunicação científica: discussão do impacto na avaliação de diferentes áreas." RECIIS. Revista eletrônica de comunicação, informação \& inovação em saúde, 2010, v. 4, pp. 3.

Samara, Timothy. Guia de design editorial. Porto Alegre: Bookman, 2011a.

Samara, Timothy. Guia de tipografia. Porto Alegre: Bookman, 2011 b.

Sayão, Luis Fernando. "Repositórios digitais confiáveis para a preservação de periódicos eletrônicos científicos." Ponto de Acesso, Salvador, 2010, v. 4, n.3, pp. 68-94.

Silva, Camila Wohlmuth da. Proposta de um guia de melhores práticas para edição de artigos de revistas científicas eletrônicas em hipermídia. Universidade Federal de Santa Catarina. Florianópolis, 2015.

Wood, Dave. Interface design: an introduction to visual communication in UI design, 2014.

Woloszyn, Maíra. Fatores de aplicação da tipografia em livros digitais. Universidade Federal de Santa Catarina. Florianópolis, 2018. 


\section{ABSTRACTS}

Scientific journals are the main form of recording and disseminating results of scientific research. After the advancement of digital media, their search, access, and navigation became easier and faster. This changes the way readers interact with the content. In this sense, the configuration of typography, an essential component of text-based publications, should facilitate the reading and understanding of the information presented. Thus, this research aimed to formalize an analysis process for the application of typography in papers on electronic scientific journals. Based on the literature review, an analysis structure was formulated. The analysis identified the fundamental principles of application of typography as: legibility, readability, spacing and font size and information hierarchy. Subsequently, four electronic papers from Brazilian scientific journals with different areas of knowledge were selected as objects of study. As a result, a potential application of typography for digital media was identified, but this potential is not fully explored by the editors of scientific journals nor by the literature dealing with the topic.

INDEX

Keywords: typography, electronic scientific journals, scientific papers, analysis

\section{AUTHORS}

\section{MAÍRA WOLOSZYN}

Universidade Federal de Santa Catarina, maira.projetar@gmail.com

(corresponding author)

ROSÂNGELA SCHWARZ RODRIGUES

Universidade Federal de Santa Catarina

\section{BERENICE SANTOS GONÇALVES}

Universidade Federal de Santa Catarina 